\title{
Climate change and allergy in Australia: an innovative, high-income country, at potential risk
}

\author{
Paul J Beggsa,b
}

a Department of Environmental Sciences, Faculty of Science and Engineering, Macquarie University, Sydney, NSW, Australia

b Corresponding author: paul.beggs@mq.edu.au

\section{Article history}

\section{Publication date: December 2018}

Citation: Beggs PJ. Climate change and allergy in Australia: an innovative, highincome country, at potential risk. Public Health Res Pract. 2018;28(4):e2841828. https://doi.org/10.17061/phrp2841828

\section{Key points}

- There are many possible pathways through which climate change could increase the public health impacts of allergic diseases

- Australia is highly vulnerable to such impacts because of its relatively high prevalence of allergic diseases such as asthma and allergic rhinitis, and allergic sensitisation to environmental allergens such as certain pollens and fungal spores

- Australian-focused research is urgently needed, as is sustainable aeroallergen monitoring, reporting and forecasting

\section{Abstract}

Objectives: The impacts of climate change on allergens and allergic diseases are important and potentially serious in Australia. Australia is highly vulnerable to such impacts because of its very high prevalence of allergic diseases such as asthma and allergic rhinitis, and allergic sensitisation to environmental allergens such as certain pollens and fungal spores. This article aims to review published research on the impacts of climate change on allergens and allergic diseases from an Australian perspective.

Methods: Research on climate change, allergens and allergy was reviewed. Recent global assessments of the topic were consulted, and supplemented with database searches to identify research published since the assessments were done, as well as research with an Australian focus. The databases used were Web of Science and Scopus. Only research published since the year 2000 was included.

Results: The impacts of climate change on allergens and allergic diseases are many and varied. Impacts on pollen include effects on pollen production and atmospheric pollen concentration, pollen seasonality, pollen allergenicity, and the dispersion and spatial distribution of pollen. Similarly, there is evidence for effects on fungal spore production, seasonality and allergenicity. There are also likely effects on indoor moisture and mould growth. Beyond these respiratory allergens, climate change may also affect food allergens, stinging insect allergens and contact allergens. All these changes could affect allergic diseases, in particular allergic respiratory diseases such as allergic asthma and allergic rhinitis.

Conclusions: A large and sophisticated body of research exists from which to gauge both current and potential future impacts of climate change on allergens and allergic diseases. However, most, if not all, of this is from outside Australia. Australian-focused research is therefore urgently needed. Australia's vulnerability to the adverse effects of climate change on allergic diseases is compounded by the precarious nature of aeroallergen monitoring, reporting and forecasting in this country. But Australia has an impressive wealth of relevant experience and expertise, and has the potential to address the challenge of both current and future impacts of climate change on allergens and allergic diseases. 


\section{Introduction}

The impacts of climate change on allergens and allergic diseases are intriguing and multifaceted. ${ }^{1}$ Internationally, they have for many years been considered among the many potential impacts of climate change on human health. ${ }^{2-4}$ The acceleration of research in this area has been astounding. We now have a large and sophisticated body of research from which to gauge potential future impacts and impacts that have already happened and with which we currently live. ${ }^{5}$

Allergy is a significant public health issue in Australia. The prevalence of allergic diseases and allergic sensitisation is high, with the prevalence of asthma being among the highest in the world. One international study found the prevalence of current wheeze and severe asthma in children in Australia to be $>20 \%$ and $>7.5 \%$, respectively. ${ }^{6}$ In a study of the geographical distribution of allergic rhinitis in adults aged 20-44 years living in 35 centres in 15 countries, the prevalence of self-reported allergic rhinitis in Australia (Melbourne) was the highest, at $31.8 \%$ (95\% confidence interval [Cl] 27.8, 35.9). ${ }^{7}$ Australia also has one of the highest prevalences of allergy to a range of common and important aeroallergens. For example, Bousquet et al. ${ }^{8}$, in the same study of 35 centres in 15 countries, found that the prevalence of allergic sensitisation to timothy grass pollen was highest in Australia (29.2\%; 95\% Cl 25.3, 33.2), and to Alternaria was third highest of the 35 centres (11.3\%; 95\% Cl 8.4, 14.2). Overall, the prevalence of allergic sensitisation in Australia was third highest of the 35 centres (49.2\%; 95\% Cl 44.8, 53.5). ${ }^{8}$

Research in Australia directly links environmental allergen exposure to important health outcomes. For example, airborne grass pollen has been associated with sales of anti-allergic medications ${ }^{9}$ and asthma emergency department presentations. ${ }^{10,11}$ Similarly, Tham et al. ${ }^{12}$ found associations between some outdoor fungal spores and asthma hospitalisations in Sydney. Further, research using a birth cohort in Melbourne, Australia, has shown that persistent pollen exposure during infancy is associated with increased risk of subsequent childhood asthma and hay fever. ${ }^{13}$ Specifically, up to 3 months cumulative exposure to pollen was associated with hay fever (adjusted odds ratio [aOR] 1.14; 95\% Cl 1.01, 1.29), and between 4 and 6 months exposure was associated with asthma only $(\mathrm{aOR} 1.35 ; 95 \% \mathrm{Cl} 1.07,1.72) .{ }^{13}$

Climate plays a major role in the lives of allergenic organisms, including their production of allergens, and in our eventual exposure to such allergens. ${ }^{5}$ For example, in Australia, variation in climate even within the city of Sydney is associated with differing allergy patterns, with those living less than $15 \mathrm{~km}$ from the coast being less commonly sensitised to grass aeroallergens than people further inland. ${ }^{14}$ Similarly, a recent study in South East Queensland found allergy to Eucalyptus pollen was significantly more common in people located on the coast compared with those living nearby in a more inland and elevated location. ${ }^{15}$

Recent synthesis and analysis of all available airborne pollen data for Australia has revealed just how important the role of climate is. The composition and relative abundance of airborne pollen in urban areas of Australia are strongly influenced by climate. ${ }^{16}$ Further, there is a striking spatial and temporal variability in grass pollen seasons in Australia. The latitudinal gradient in climate influences the average length of the grass pollen season, and the start date, end date and duration of the pollen season often vary substantially from one year to the next at any particular site. ${ }^{17,18}$

Australia is highly vulnerable to any adverse impact of climate change on allergens and allergic diseases. This underlying vulnerability was highlighted in November 2016 when the world's largest, most catastrophic epidemic thunderstorm asthma event occurred in Melbourne. The event was triggered by a sequence of environmental conditions culminating in extreme airborne grass pollen concentrations. This resulted in thousands of excess respiratory-related emergency department presentations, hundreds of excess asthma-related hospital admissions, 35 intensive care unit admissions and 10 deaths $^{19}$, and placed unprecedented demands on health and emergency services. ${ }^{20}$

Climate is changing in Australia as it is elsewhere, and significant changes have already been observed in factors relevant to allergens and allergic diseases. For plants, for example, changes in temperature, precipitation and other climate factors, as well as the increasing atmospheric concentrations of carbon dioxide, are of great significance. The aim of this article is to review the impacts of such changes on allergens and allergic diseases, and to reflect on the associated research effort in Australia.

\section{Methods}

International and Australian research on climate change, allergens and allergy was reviewed. Although the impacts of climate change on allergens and allergic diseases were assessed globally in $2016^{5}$, this source was supplemented with database searches to identify research published since this time, as well as research with an Australian focus. The databases used were Web of Science and Scopus, and searches used combinations of relevant terms including "Australia", "carbon dioxide", "climate change", "temperature", "allergy", "allergies", "asthma", "allergic rhinitis", "hay fever", "allergen", "pollen" and "environmental allergens". Only research published since the year 2000 was included. 


\section{Results}

The impacts of climate change on allergens and allergic diseases are many and varied. ${ }^{21-23}$ Impacts on pollen include effects on pollen production and atmospheric pollen concentration, pollen seasonality, pollen allergenicity, and the dispersion and spatial distribution of pollen. Similarly, there is evidence for effects on fungal spore production, seasonality and allergenicity. There are also likely effects in the indoor environment, including effects on indoor moisture and mould growth. Beyond these respiratory allergens, climate change may also affect food allergens, stinging insect allergens and contact allergens. All these changes could affect allergic diseases, in particular allergic respiratory diseases such as allergic asthma and allergic rhinitis. The remainder of this section discusses each of these impacts in turn, with examples of the evidence we currently have for them.

Experimental research, modelling and environmental monitoring provide evidence for impacts of climate change on pollen amount. Perhaps the best environmental study to date has been conducted in Europe, analysing more than 1200 pollen time series (some almost 30 years long) from 23 pollen taxa at almost 100 locations in 13 European countries. ${ }^{24}$ It revealed an increasing trend in the yearly amount of airborne pollen for many taxa in Europe. It also found that increased temperatures did not appear to be a major influencing factor, and instead suggested the rise of atmospheric $\mathrm{CO}_{2}$ levels may be influential. ${ }^{24}$

Similar research has documented important impacts of climate change on pollen seasonality. Ziska et al. ${ }^{25}$ reported that recent warming at various latitudes was associated with an observed increased length of the ragweed pollen season in central North America. Indeed, the study reported that the length of the ragweed pollen season had increased by as much as 13-27 days at latitudes above about 44으 since $1995 .{ }^{25}$ Ragweed pollen is an important aeroallergen, with research showing that the prevalence of sensitisation is about $10 \%$ in the US, where it is a main cause of allergic diseases. ${ }^{8,26}$

Pollen allergenicity has also been studied in relation to climate change. One recent example is the experimental study by El Kelish et al. ${ }^{26}$ of ragweed under an elevated atmospheric $\mathrm{CO}_{2}$ concentration (at a level projected to occur in the future) and drought stress. The study showed that ragweed pollen would likely become more allergenic under conditions of elevated $\mathrm{CO}_{2}$, drought stress, and elevated $\mathrm{CO}_{2}$ plus drought stress. Another recent experimental study, by Albertine et al. ${ }^{27}$, examined the impact of elevated $\mathrm{CO}_{2}$ and ozone $\left(\mathrm{O}_{3}\right)$ on timothy grass pollen and allergen production. While elevated $\mathrm{O}_{3}$ reduced the allergen content of the pollen, the elevated $\mathrm{CO}_{2}$ increased the amount of grass pollen produced to such an extent (by about 50\% per flower) that the net effect of elevated levels of both gases would likely be increased allergen exposure. ${ }^{27}$
In addition to impacts on pollen amount, seasonality and allergenicity, climate change affects the dispersion and spatial distribution of pollen. ${ }^{28}$ Two recent studies ${ }^{29,30}$ have used a modelling approach to project the potential future distribution of ragweed under climate change conditions. The studies provide evidence for a significant northward expansion of ragweed habitat in both Europe and North America in the future.

Studies also indicate that fungal spore exposure is affected by climate change. For example, Wolf et al. ${ }^{31}$ have shown experimentally that the fungus Alternaria, when grown on leaves of timothy grass plants grown at potential future elevated $\mathrm{CO}_{2}$ concentrations, produces nearly three times the number of spores and more than twice the total antigenic protein per plant than at lower $\mathrm{CO}_{2}$ concentrations.

Although changes in climate averages are important, so too are changes in climate and weather extremes. As noted earlier, thunderstorms can be associated with epidemics of asthma exacerbation. Tropical cyclones can also be associated with outbreaks of allergic disease as a result of the prolific growth of mould from flooding and water-damaged dwellings, as occurred in New Orleans following Hurricane Katrina. ${ }^{32}$ With such extreme meteorological events projected to increase in frequency and/or severity in the future ${ }^{33-35}$, it is to be expected that their interactions with allergens and allergic diseases may change accordingly.

There have also been suggestions that climate change may affect food allergens, such as those in peanuts. ${ }^{36}$ This is perhaps the most understudied area with respect to the impacts of climate change on allergens. One recent field study of the effects of elevated $\mathrm{CO}_{2}$ on two peanut (Arachis hypogaea L.) cultivars ${ }^{37}$ found an overall significant $6 \%$ increase in the concentration of the primary peanut allergen (Ara h 1). However, only one of the cultivars, 'Virginia Jumbo', showed increases in both of the years studied. In the other cultivar, 'Georgia Green', the concentration increased in the first year but decreased in the second year.

Stinging insects can cause allergic reactions, including life-threatening anaphylaxis, in people with an allergy to the insect's venom. The spatial distribution of stinging insects, like that of plants and other animals, is directly related to temperature, and a warming world will bring with it impacts on the distributions of stinging insects. Similarly, the seasonality and abundance of stinging insects is likely to be affected by climate change. For example, in just the last decade or so, imported fire ant populations have been discovered in Australia, where they pose a serious public health threat to the human population by envenomation and subsequent allergic reactions. ${ }^{38}$ With research showing that fire ant colony size is largest during years with higher daily temperature, it has been suggested that future temperature increases may facilitate population growth. ${ }^{28}$ 
Finally, climate change has been shown to affect plants that cause skin reactions (contact dermatitis), which may have adverse public health consequences. For example, in a field experiment in the US, researchers showed that poison ivy plants grown under elevated atmospheric $\mathrm{CO}_{2}$ produced a more allergenic or toxic form of the active compound urushiol. ${ }^{39}$

The broad, varied and substantial impacts of climate change on allergens would be expected to have similarly broad, varied and substantial impacts on allergic diseases. Indeed, it has been hypothesised that climate change is a plausible contributor to the global rise in asthma that has taken place since the 1960s, including in Australia. ${ }^{40}$ The American Thoracic Society recently surveyed its international members to assess perceptions and clinical experiences related to global climate change. ${ }^{41}$ A majority of respondents indicated that they are already observing health impacts of climate change among their patients, with the second most common cause (reported by $72 \%$ of respondents) being increases in allergic symptoms from exposure to plants or fungi. ${ }^{41}$ An even larger majority (76\%) anticipated seeing these climate-related health impacts in the next two decades. ${ }^{41}$

Scientific studies of the impacts of climate change on allergic diseases do exist but they are in limited supply. Two examples, again from the Northern Hemisphere, serve to illustrate these. Research has shown that medical visits for insect reactions have increased significantly in Alaska, US, in association with increasing temperatures there. ${ }^{42}$ And in one of the most significant studies in this field to date, Lake et al. ${ }^{43}$ used a modelling approach to produce perhaps the first quantification of the consequences of climate change on pollen allergy, focusing on ragweed pollen allergy in Europe. Building on earlier work ${ }^{30,44}$, this research indicated that sensitisation to ragweed will more than double in Europe, from 33 million to 77 million people, by 2041-206043 and that the severity of symptoms may also increase. This study emphasised the multiple steps required to model the impact of climate change on pollen allergy, and that there are assumptions and uncertainties associated with each step of the process. ${ }^{43}$

\section{Discussion}

Climate change is the biggest global health threat of the 21 st century, and tackling it could be the greatest global health opportunity of this century. ${ }^{45,46}$ These conclusions apply to the impacts of climate change on allergic diseases (and many other conditions). Given the concerning status of allergic diseases in Australia, it could be argued that these impacts pose a serious climate change-human health risk to Australia and that they should therefore be among Australia's climate change-human health priorities.

The above research on the impacts of climate change on allergens and allergic diseases is relevant to Australia. For example, experimental results from Albertine et al. ${ }^{27}$ that showed increased timothy grass pollen allergen exposure under projected future climate conditions are of direct relevance and importance to Australia, given the very high prevalence of allergic sensitisation to timothy grass pollen in Australia (29.2\%). Similarly, Wolf et al. ${ }^{31}$ showed that overall Alternaria spore total antigenic protein increased with projected future $\mathrm{CO}_{2}$ concentrations, which is a concern given the high prevalence of sensitisation to this fungus in Australia and its association with childhood and adolescent asthma hospitalisations. ${ }^{47}$

However, there are limitations in the research on the impacts of climate change on allergens and allergic diseases that should be noted. ${ }^{48}$ For example, observational studies such as those by Ziello et al. ${ }^{24}$ and Ziska et al. ${ }^{25}$ are limited in space and time, and confined to locations and the period for which atmospheric pollen concentration records are available. While experimental studies such as those by El Kelish et al. ${ }^{26}$ and Albertine et al. ${ }^{27}$ can provide a better functional understanding and a greater insight into the underlying mechanisms ${ }^{48}$ of the impacts of climate change on pollen production and allergenicity, they are limited in their ability to replicate the complexity of the environmental conditions in which the plant exists beyond the laboratory. Finally, modelling studies such as those by Chapman et al. ${ }^{29}$ and Storkey et al. ${ }^{30}$, while enabling examination of the impacts of climate change on allergenic plants over long periods of time (both past and future) and vast areas, are limited by our understanding of allergenic plant biology and ecology.

Little if any of the research on the impacts of climate change on allergens and allergic diseases has been focused on Australia. Such Australian-focused research is therefore urgently needed. There are many gaps in our knowledge and there is much research to be done, but a high priority is experimental research examining the effects of increased temperature and atmospheric carbon dioxide concentration on production, allergenicity and seasonality of aeroallergens of clinical and public health significance in Australia. But it is also appropriate here to reflect on other aspects of Australia's vulnerability to, and potential to adapt to ${ }^{49}$, the impacts of climate change on allergic diseases.

Environmental allergen monitoring, reporting and forecasting is a public health policy and practice gap in Australia. Unlike weather and climate, which are serviced excellently for the whole country by the Australian Bureau of Meteorology, and chemical air pollutants, which are similarly well serviced by state and territory environment protection authorities and the like, no national or state/ territory body has responsibility for the monitoring, reporting and forecasting of environmental allergens such as airborne pollen and fungal spores.

Monitoring in Australia at present remains sparse, with the exceptions of Tasmania and Victoria where several monitors are spread across the state, and perhaps the Australian Capital Territory where a single monitor 
may adequately represent the relatively small area. Monitoring also remains sporadic in some locations, with, for example, Melbourne's, and indeed all of Victoria's, monitors operating just over the 3-month period October to December, while other sites such as those in Sydney operate year round. And despite the best efforts of those engaged in this monitoring around Australia, its continuation into the future is always at risk, with all sites either unfunded or on relatively limited and short-term funding.

However, Australia has an impressive wealth of relevant experience and expertise, with the breadth and depth required to address the challenge of both current and future impacts on allergens and allergic diseases. Since 2013, initially through an Australian Aerobiology Working Group, and more recently as the AusPollen Partnership, experts in botany, palynology, biogeography, climate change science, plant genetics, biostatistics, ecology, pollen allergy, public and environmental health, and medicine have come together to collaborate on Australian aeroallergen research and public health practice. ${ }^{50}$ This transdisciplinary partnership has achieved a great deal in a relatively short period of time. ${ }^{16-18,50,51}$

Australia has demonstrated its capacity to innovate at the cutting edge of this field. Three current examples serve to illustrate this point:

- Australian research has demonstrated the potential of satellite remote sensing of grass seasonal greenness to augment forecast models of airborne grass pollen as a tool to reduce the health and socio-economic burden of pollen-sensitive allergic diseases. ${ }^{51}$

- Australian research teams are using smartphone technology to publicly report measured airborne pollen levels, and as a means of symptom surveillance. Consistent with international calls for an approach to assessing, forecasting and communicating air quality that integrates the physical, chemical and biological components ${ }^{52}$, one Australian smartphone app (AirRater) tracks exposure to three key environmental hazards - temperature, air particles $\left(\mathrm{PM}_{2.5}\right)$ and aeroallergens. ${ }^{53}$ Such technologies improve patient understanding of how environmental conditions affect their health, and provide them with a means to better manage their disease. ${ }^{53}$

- Following the deadly epidemic thunderstorm asthma event in Melbourne in November 2016, and the injection of $\$ 15$ million by the Victorian State Government towards implementing a multipronged response that would avoid another such event, a large and multidisciplinary Australian team has developed and put into practice the world's first thunderstorm asthma forecasting system. ${ }^{54}$
Australia has now embarked on a broad-ranging and in-depth annual assessment of its progress on climate change and human health, paralleling the Lancet Countdown's global assessment. ${ }^{55}$ While the response to the Melbourne epidemic thunderstorm asthma event since November 2016 has been extensive and swift in Victoria, this response is perhaps just the tip of the iceberg compared with the work that lies ahead of us in understanding the impacts of climate change on allergens and allergic diseases in the Australian context, and then responding with appropriate public health adaptation and practice.

\section{Conclusion}

Although a large and sophisticated body of research exists from which to gauge both current and potential future impacts of climate change on allergens and allergic diseases, most, if not all, of this is from outside Australia. Australian-focused research is therefore urgently needed. Australia's potential vulnerability to the adverse impacts of climate change on allergic diseases is compounded by the precarious nature of aeroallergen monitoring, reporting and forecasting in this country. But Australia has an impressive wealth of relevant experience and expertise, with the potential to address the challenge of both current and future impacts of climate change on allergens and allergic diseases.

\section{Acknowledgements}

The assistance of Jane Al Kouba is gratefully acknowledged.

\section{Peer review and provenance}

Externally peer reviewed, commissioned.

\section{Competing interests}

None declared.

\section{Author contributions}

$\mathrm{PB}$ is the sole author of this work.

\section{References}

1. Beggs PJ. Impacts of climate change on allergens and allergic diseases: knowledge and highlights from two decades of research. In: Butler CD, ed. Climate change and global health. Wallingford, UK: CAB International; 2014. pp. 105-13. 
2. Hunter DJ, Frumkin $\mathrm{H}$, Jha A. Preventive medicine for the planet and its peoples. N Engl J Med. 2017;376(17):1605-7.

3. Smith KR, Woodward A, Campbell-Lendrum D, Chadee DD, Honda Y, Liu Q, et al. Human health: impacts, adaptation, and co-benefits. In: Field CB, Barros VR, Dokken DJ, Mach KJ, Mastrandrea MD, Bilir TE, et al., eds. Climate change 2014: impacts, adaptation, and vulnerability. Part A: Global and sectoral aspects. Contribution of Working Group II to the Fifth Assessment Report of the Intergovernmental Panel on Climate Change. Cambridge, UK and New York, NY, US: Cambridge University Press; 2014. pp. 709-54.

4. World Health Organization. Protecting health in Europe from climate change: 2017 update. Copenhagen: World Health Organization; 2017 [cited 9 May 2018]. Available from: www.euro. who.int/_data/assets/pdf_file/0004/355792/ ProtectingHealthEuropeFromClimateChange.pdf?ua=1

5. Beggs PJ, ed. Impacts of climate change on allergens and allergic diseases. Cambridge, England: Cambridge University Press; 2016.

6. Lai CKW, Beasley R, Crane J, Foliaki S, Shah J, Weiland $S$, et al. Global variation in the prevalence and severity of asthma symptoms: phase three of the International Study of Asthma and Allergies in Childhood (ISAAC). Thorax. 2009;64(6):476-83.

7. Bousquet P-J, Leynaert B, Neukirch F, Sunyer J, Janson $\mathrm{CM}$, Anto J, et al. Geographical distribution of atopic rhinitis in the European Community Respiratory Health Survey I. Allergy. 2008;63(10):1301-9.

8. Bousquet P-J, Chinn S, Janson C, Kogevinas M, Burney $P$, Jarvis D. Geographical variation in the prevalence of positive skin tests to environmental aeroallergens in the European Community Respiratory Health Survey I. Allergy. 2007;62(3):301-9.

9. Johnston FH, Hanigan IC, Bowman DMJS. Pollen loads and allergic rhinitis in Darwin, Australia: a potential health outcome of the grass-fire cycle. Ecohealth. 2009;6(1):99-108.

10. Erbas B, Akram M, Dharmage SC, Tham R, Dennekamp $\mathrm{M}$, Newbigin $\mathrm{E}$, et al. The role of seasonal grass pollen on childhood asthma emergency department presentations. Clin Exp Allergy. 2012;42(5):799-805.

11. Hayden TJ, Muscatello DJ. Increased presentations to emergency departments for asthma associated with rye grass pollen season in inland NSW. N S W Public Health Bull. 2011;22(7-8):154-8.

12. Tham R, Katelaris $\mathrm{CH}$, Vicendese D, Dharmage SC, Lowe AJ, Bowatte $G$, et al. The role of outdoor fungi on asthma hospital admissions in children and adolescents: a 5-year time stratified case-crossover analysis. Environ Res. 2017; 154:42-9.

13. Erbas B, Lowe AJ, Lodge CJ, Matheson MC, Hosking CS, Hill DJ, et al. Persistent pollen exposure during infancy is associated with increased risk of subsequent childhood asthma and hayfever. Clin Exp Allergy. 2013;43(3):337-43.
14. Kam AW, Tong WWY, Christensen JM, Katelaris CH, Rimmer J, Harvey RJ. Microgeographic factors and patterns of aeroallergen sensitisation. Med J Aust. 2016;205(7):310-5.

15. Gibbs JEM. Eucalyptus pollen allergy and asthma in children: a cross-sectional study in South-East Queensland, Australia. PLoS One. 2015;10(5):e0126506.

16. Haberle SG, Bowman DMJS, Newnham RM, Johnston $\mathrm{FH}$, Beggs PJ, Buters J, et al. The macroecology of airborne pollen in Australian and New Zealand urban areas. PLoS One. 2014;9(5):e97925.

17. Beggs PJ, Katelaris CH, Medek D, Johnston FH, Burton $\mathrm{PK}$, Campbell B, et al. Differences in grass pollen allergen exposure across Australia. Aust N Z J Public Health. 2015;39(1):51-5.

18. Medek DE, Beggs PJ, Erbas B, Jaggard AK, Campbell $B C$, Vicendese $D$, et al. Regional and seasonal variation in airborne grass pollen levels between cities of Australia and New Zealand. Aerobiologia (Bologna). 2016;32(2):289-302.

19. Thien F, Beggs PJ, Csutoros D, Darvall J, Hew M, Davies $\mathrm{JM}$, et al. The Melbourne epidemic thunderstorm asthma event 2016: an investigation of environmental triggers, effect on health services, and patient risk factors. Lancet Planet Health. 2018;2(6):e255-63.

20. Inspector-General for Emergency Management. Review of response to the thunderstorm asthma event of 21-22 November 2016: final report. Melbourne: Department of Justice and Regulation, Victoria State Government; 2017 April [cited 7 November 2018]. Available from: www.igem.vic.gov.au/sites/default/files/embridge_ cache/emshare/original/public/2017/07/80/c414fe2ba/ ReviewofemergencyresponsetoNovember2016 thunderstormasthmaeventfinalreport.pdf

21. Beggs PJ. Impacts of climate change on aeroallergens: past and future. Clin Exp Allergy. 2004;34(10):1507-13.

22. Katelaris $\mathrm{CH}$, Beggs PJ. Climate change: allergens and allergic diseases. Intern Med J. 2018;48(2):129-34.

23. Ziska LH, Beggs PJ. Anthropogenic climate change and allergen exposure: the role of plant biology. J Allergy Clin Immunol. 2012;129(1):27-32.

24. Ziello C, Sparks TH, Estrella N, Belmonte J, Bergmann $\mathrm{KC}$, Bucher $\mathrm{E}$, et al. Changes to airborne pollen counts across Europe. PLoS One. 2012;7(4):e34076.

25. Ziska L, Knowlton K, Rogers C, Dalan D, Tierney N, Elder MA, et al. Recent warming by latitude associated with increased length of ragweed pollen season in central North America. Proc Natl Acad Sci U S A. 2011;108(10):4248-51.

26. El Kelish A, Zhao F, Heller W, Durner J, Winkler JB, Behrendt $\mathrm{H}$, et al. Ragweed (Ambrosia artemisiifolia) pollen allergenicity: SuperSAGE transcriptomic analysis upon elevated $\mathrm{CO}_{2}$ and drought stress. BMC Plant Biol. 2014; $14: 176$. 
27. Albertine JM, Manning WJ, DaCosta M, Stinson KA, Muilenberg ML, Rogers CA. Projected carbon dioxide to increase grass pollen and allergen exposure despite higher ozone levels. PLoS One. 2014;9(11):e111712.

28. Beaumont LJ, Duursma DE. Impacts of climate change on the distributions of allergenic species. In: Beggs PJ, ed. Impacts of climate change on allergens and allergic diseases. Cambridge, England: Cambridge University Press; 2016. pp. 29-49.

29. Chapman DS, Haynes T, Beal S, EssI F, Bullock JM. Phenology predicts the native and invasive range limits of common ragweed. Glob Chang Biol. 2014;20(1):192-202.

30. Storkey J, Stratonovitch P, Chapman DS, Vidotto F, Semenov MA. A process-based approach to predicting the effect of climate change on the distribution of an invasive allergenic plant in Europe. PLoS One. 2014;9(2):e88156.

31. Wolf J, O'Neill NR, Rogers CA, Muilenberg ML, Ziska LH. Elevated atmospheric carbon dioxide concentrations amplify Alternaria alternata sporulation and total antigen production. Environ Health Perspect. 2010;118(9):1223-8.

32. Beggs PJ, Bennett CM. Climate change, aeroallergens, natural particulates, and human health in Australia: state of the science and policy. Asia Pac J Public Health. 2011;23(2 Suppl):46S-53S

33. Allen JT, Karoly DJ, Walsh KJ. Future Australian severe thunderstorm environments. Part II: The influence of a strongly warming climate on convective environments. J Clim. 2014;27(10):3848-68.

34. Singh MS, Kuang Z, Maloney ED, Hannah WM, Wolding $\mathrm{BO}$. Increasing potential for intense tropical and subtropical thunderstorms under global warming. Proc Natl Acad Sci U S A. 2017;114(44):11657-62.

35. Parker CL, Bruyère CL, Mooney PA, Lynch AH. The response of land-falling tropical cyclone characteristics to projected climate change in northeast Australia. Clim Dyn. 2018;51(9-10):3467-85.

36. Beggs PJ, Walczyk NE. Impacts of climate change on plant food allergens: a previously unrecognized threat to human health. Air Qual Atmos Health. 2008;1(2):119-23.

37. Ziska LH, Yang J, Tomecek MB, Beggs PJ. Cultivarspecific changes in peanut yield, biomass, and allergenicity in response to elevated atmospheric carbon dioxide concentration. Crop Sci. 2016;56(5):2766-74.

38. Porter SD, Oi DH, Valles SM, Vander Meer RK. Mitigating the allergic effects of fire ant envenomation with biologically based population reduction. Curr Opin Allergy Clin Immunol. 2013;13(4):372-8.

39. Mohan JE, Ziska LH, Schlesinger WH, Thomas RB, Sicher RC, George K, et al. Biomass and toxicity responses of poison ivy (Toxicodendron radicans) to elevated atmospheric $\mathrm{CO}_{2}$. Proc Natl Acad Sci U S A 2006;103(24):9086-9.
40. Beggs PJ, Bambrick HJ. Is the global rise of asthma an early impact of anthropogenic climate change? Environ Health Perspect. 2005;113(8):915-9.

41. Sarfaty M, Kreslake J, Ewart G, Guidotti TL, Thurston GD, Balmes JR, et al. Survey of international members of the American Thoracic Society on climate change and health. Ann Am Thorac Soc. 2016;13(10):1808-13.

42. Demain JG, Gessner BD, McLaughlin JB, Sikes DS, Foote JT. Increasing insect reactions in Alaska: is this related to changing climate? Allergy Asthma Proc. 2009;30(3):238-43.

43. Lake IR, Jones NR, Agnew M, Goodess CM, Giorgi F, Hamaoui-Laguel L, et al. Climate change and future pollen allergy in Europe. Environ Health Perspect. 2017;125(3):385-91.

44. Hamaoui-Laguel L, Vautard R, Liu L, Solmon F, Viovy N, Khvorostyanov D, et al. Effects of climate change and seed dispersal on airborne ragweed pollen loads in Europe. Nat Clim Chang. 2015;5:766-71.

45. Costello A, Abbas M, Allen A, Ball S, Bell S, Bellamy R, et al. Managing the health effects of climate change. Lancet. 2009;373(9676):1693-733.

46. Watts N, Adger WN, Agnolucci P, Blackstock J, Byass P, Cai $W$, et al. Health and climate change: policy responses to protect public health. Lancet. 2015;386(10006):1861-914.

47. Tham R, Vicendese D, Dharmage SC, Hyndman RJ, Newbigin E, Lewis E, et al. Associations between outdoor fungal spores and childhood and adolescent asthma hospitalizations. J Allergy Clin Immunol. 2017;139(4):1140-7.

48. Spiegelberger T, Gillet F, Amiaud B, Thébault A, Mariotte P, Buttler A. How do plant community ecologists consider the complementarity of observational, experimental and theoretical modelling approaches? Plant Ecol Evol. 2012;145(1):4-12.

49. Beggs PJ. Adaptation to impacts of climate change on aeroallergens and allergic respiratory diseases. Int J Environ Res Public Health. 2010;7(8):3006-21.

50. Davies JM, Beggs PJ, Medek DE, Newnham RM, Erbas $\mathrm{B}$, Thibaudon $\mathrm{M}$, et al. Trans-disciplinary research in synthesis of grass pollen aerobiology and its importance for respiratory health in Australasia. Sci Total Environ. 2015;534:85-96.

51. Devadas R, Huete AR, Vicendese D, Erbas B, Beggs PJ, Medek D, et al. Dynamic ecological observations from satellites inform aerobiology of allergenic grass pollen. Sci Total Environ. 2018;633:441-51.

52. Klein T, Kukkonen J, Dahl Å, Bossioli E, Baklanov A, Vik $A F$, et al. Interactions of physical, chemical, and biological weather calling for an integrated approach to assessment, forecasting, and communication of air quality. Ambio. 2012;41(8):851-64. 
53. Johnston FH, Wheeler AJ, Williamson GJ, Campbell SL, Jones PJ, Koolhof IS, et al. Using smartphone technology to reduce health impacts from atmospheric environmental hazards. Environ Res Lett. 2018;13(4):044019.

54. Kornei K. Australian state forecasts deadly thunderstorm asthma: scientists probe ways that storms weaponize pollen. Science. 2018;359(6374):380.
55. Zhang Y, Beggs PJ. The Lancet Countdown down under: tracking progress on health and climate change in Australia. Med J Aust. 2018;208(7):285-6.

\section{Copyright: (c) (i) (2)}

(C) 2018 Beggs. This article is licensed under the Creative Commons Attribution-NonCommercial-ShareAlike 4.0 International Licence, which allows others to redistribute, adapt and share this work non-commercially provided they attribute the work and any adapted version of it is distributed under the same Creative Commons licence terms. See: www.creativecommons.org/licenses/by-nc-sa/4.0/ 